\title{
SiC Conversion Coating Prepared from Silica-Graphite Reaction
}

\author{
Back-Sub Sung ${ }^{1}$ and Young-Hoon Yun ${ }^{2}$ \\ ${ }^{1}$ Department of Mechanical Engineering, Chosun University, Gwangju 501-759, Republic of Korea \\ ${ }^{2}$ Department of Hydrogen \& Fuel Cell Tech., Dongshin University, Jeonnam 520-714, Republic of Korea \\ Correspondence should be addressed to Young-Hoon Yun; yunh2@dsu.ac.kr
}

Received 4 September 2016; Revised 7 December 2016; Accepted 13 December 2016; Published 14 February 2017

Academic Editor: Pavel Lejcek

Copyright (C) 2017 Back-Sub Sung and Young-Hoon Yun. This is an open access article distributed under the Creative Commons Attribution License, which permits unrestricted use, distribution, and reproduction in any medium, provided the original work is properly cited.

\begin{abstract}
The $\beta$-SiC conversion coatings were successfully synthesized by the $\mathrm{SiO}(\mathrm{v})$-graphite(s) reaction between silica powder and graphite specimen. This paper is to describe the effects on the characteristics of the SiC conversion coatings, fabricated according to two different reaction conditions. FE-SEM, FE-TEM microstructural morphologies, XRD patterns, pore size distribution, and oxidation behavior of the SiC-coated graphite were investigated. In the XRD pattern and SAD pattern, the coating layers showed cubic SiC peak as well as hexagonal SiC peak. The SiC coatings showed somewhat different characteristics with the reaction conditions according to the position arrangement of the graphite samples. The $\mathrm{SiC}$ coating on graphite, prepared in reaction zone (2), shows higher intensity of beta-SiC main peak (111) in XRD pattern as well as rather lower porosity and smaller main pore size peak under $1 \mu \mathrm{m}$.
\end{abstract}

\section{Introduction}

Graphite is attractive material for high temperature applications due to its high strength, high modulus, excellent thermal shock resistance, light weight, and ease in machining. It has been used as the engineering materials, like heaters, electrical contacts, high temperature heat exchangers, rocket nozzles and leading edges of aircraft wings, and so forth $[1,2]$. A serious disadvantage to the use of graphite is that it begins to oxidize to a gaseous phase at temperatures of $500^{\circ} \mathrm{C}$ with a consequent loss of material. Thus the use of graphite material has been greatly restricted due to the poor oxidation resistance at high temperature in an oxidizing atmosphere. Good oxidation resistance is necessary in their high temperature applications [3].

A silicon carbide $(\mathrm{SiC})$ coating is effective in developing the oxidation resistance and the wear resistance of graphite materials and $\mathrm{C} / \mathrm{C}$ composites, because silicon carbide has good oxidation wear resistance and high hardness. Thus it has been used as several mechanical components and ceramic engine parts, aerospace and aircraft applications, Si-wafer pot, gas turbine component, and nozzle materials [4].
To prevent a severe oxidation behavior of graphite, it is necessary to form a protective $\mathrm{SiC}$ coating of the surface of the graphite. There have been several efforts to develop such $\mathrm{SiC}$ coating processes for the graphite. The previous studies were mainly concerned with the formation of $\mathrm{SiC}$ coatings on graphite substrates using RF sputtering with a sintered $\mathrm{SiC}$ target [5]. Chemical vapor deposition (CVD) method has been widely utilized in fabricating coating. However, the $\mathrm{SiC}$ coating layers for complex shape components can be easily formed by chemical vapor reaction method $[6,7]$. The SiC conversion layer obtained by such solid-vapor reaction has good adherence with graphite matrix. The conversion coating process is based on carbothermal reduction, in which silica reduction is carried out with carbon source. This process is independent of the molar ratio of silica to carbon; in the end, silica reduction with $\mathrm{SiC}$ source is excluded in overall process $\left(\mathrm{SiO}_{2}+3 \mathrm{C} \rightarrow \mathrm{SiC}+2 \mathrm{CO}\right)[6]$. Of particular importance to $\mathrm{SiC}$ phase nucleation is $\mathrm{SiO}$ generation from silica-carbon reaction [8]. With the formation of $\mathrm{SiO}, \mathrm{CO}$ vapor $\left(\mathrm{SiO}_{2}+\mathrm{C}\right.$ $\rightarrow \mathrm{SiO}+\mathrm{CO}$ ), the $\mathrm{SiC}$ polycrystalline phase on the surface of graphite is coated through such reduction behavior between $\mathrm{SiO}$ and carbon source $(\mathrm{SiO}+2 \mathrm{C} \rightarrow \mathrm{SiC}+\mathrm{CO})$ [9-13]. 


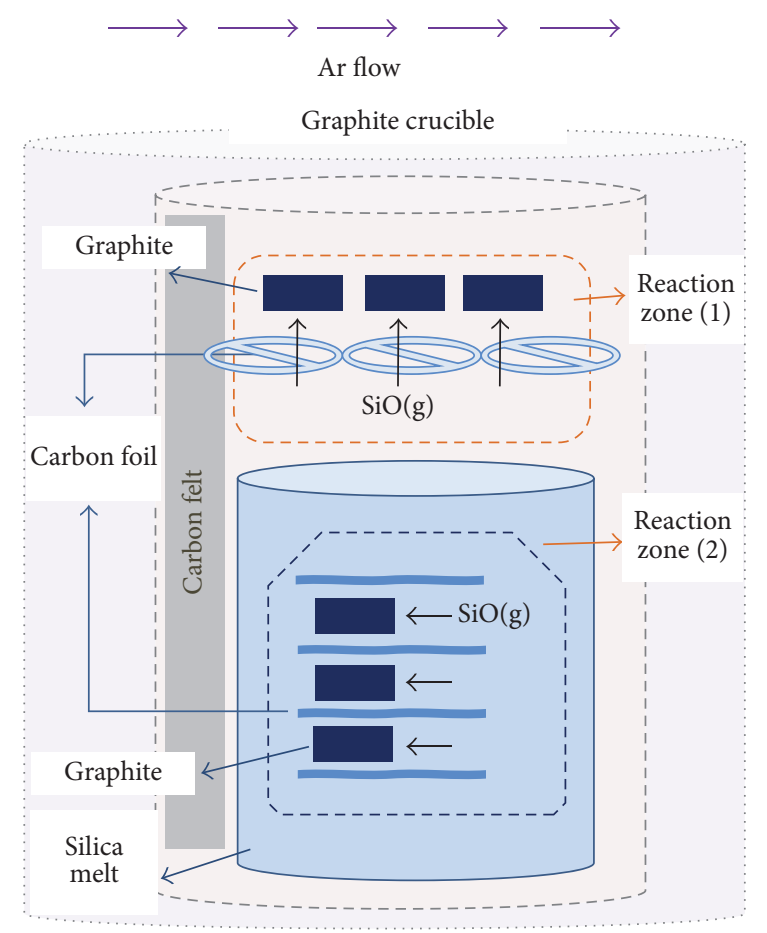

FIGURE 1: Schematic of chemical vapor reaction process for conversion coating.

Generally, the $\mathrm{SiC}$ crystal phase, produced from the $\mathrm{SiO}$ vapor and graphite at high temperature over $1500^{\circ} \mathrm{C}$, shows mainly cubic structure of 3C type with hexagonal SiC phase [13]. During heat treatment or annealing at high temperature, the cubic SiC phase might be transformed into hexagonal $\mathrm{SiC}$ phase through solid-state transformation such as closepacked layer (111) shift or spreading of stacking faults [14, 15].

In this study, the $\mathrm{SiC}$ conversion coatings were formed on the graphite substrates by conversion reaction method through the carbothermal reduction process of the silica powder and graphite. The crystal phase analysis and microstructure observation for the conversion layer on graphite were performed. Oxidation behavior and pore size distribution of the SiC conversion coating layers, formed over graphite, were investigated.

\section{Experimental}

In this work, silica $\left(\mathrm{SiO}_{2}\right)$ powder (average particle size: $3 \mu \mathrm{m}$, NOA Technology, USA) and finely ground graphite were used to form the $\mathrm{SiC}$ conversion layers. Silica powder and graphite substrate (IG-11, density: $1.77 \mathrm{~g} / \mathrm{cm}^{3}$, Toyo Tanso Co., Japan) were placed in a graphite crucible and then heated to $1750^{\circ} \mathrm{C}$. The outside of the graphite crucible was controlled with constant Ar gas flow. The reaction conditions and the $\mathrm{SiO}$ and $\mathrm{CO}$ partial pressures during the conversion process were controlled with the graphite architecture designed (Figure 1). The inside of the graphite crucible was coated with spraycoated $\mathrm{BN}$ and covered with graphite foil to prevent reaction with the silica melt. The conversion coatings were fabricated in two different reaction zones (Figure 1). The specimens in reaction zone (1) were placed on the gas-permeable carbon foil brides fixed to graphite crucible wall and reaction zone (2) was confined with silica melt.

$\mathrm{SiC}$ conversion layers on the graphite were analyzed using an X-ray diffractometer (X'Pert Pro, Phillips). Surface morphologies of the $\mathrm{SiC}$ conversion layer were observed by FESEM (Hitachi S-4800, Japan). The oxidation behavior of the $\mathrm{SiC}$ coating layer formed on the graphite was investigated by DSC/TGA (differential scanning calorimetry/thermogravimetric analysis) and differential scanning calorimeter (DSC SDT Q600, TA instruments). The SiC-coated graphite in the DSC/TGA instrument was heated to $700^{\circ} \mathrm{C}$ under flowing Ar gas; the specimens were exposed at this temperature over $2 \mathrm{hrs}$, blowing air at a rate of $100 \mathrm{~mL} / \mathrm{min}$. The pore size distribution of the $\mathrm{SiC}$ coating was analyzed by mercury intrusion porosimetry (AutoPore IV 9500 Micromeritics Instrument). Microstructure and diffraction patterns of the fragment samples separated from coating layer were analyzed by $200 \mathrm{kV}$ FE-TEM (Field Emission Transmission Electron Microscope, Tecnai G2 F20).

\section{Results and Discussion}

The chemical conversion reaction process in formation of $\mathrm{SiC}$ coating on graphite substrate has been accomplished within two reaction zones having different $\mathrm{SiO}$ partial pressure in the graphite architecture. The SiC conversion coatings were formed on the surface of graphite substrates under two reaction zones. The surface morphologies of SiC conversion coatings formed on graphite are visible in FE-SEM images (Figure 2). Relatively dense morphology of $\mathrm{SiC}$ conversion coating was observed in surface images. It seemed that the graphite (coke) grains and the pitch were changed into the closely bonded-SiC grains in coating layer during the conversion process. FEM surface image of the conversion layer obtained at reaction zone (1) showed rather a porous morphology, but that of reaction zone (2) showed relatively dense microstructure.

Cross-sectional microstructure of the polished specimen, prepared by $\mathrm{SiC}$ coating process, is shown in Figure 3. The conversion coating layer on graphite, fabricated in reaction zone (2), showed a chemical composition ( $\mathrm{Si}: \mathrm{C}$ ) of approximately $1: 1$. The boundary between $\mathrm{SiC}$ coating layer and graphite showed somewhat mixed pattern showing composition gradient of $\mathrm{SiC}$ phase and matrix graphite. Reaction zone (1), arranged on the carbon foil bridges, would have the reaction condition of a low $\mathrm{SiO}$ vapor pressure. But the $\mathrm{SiO}$ vapor partial pressure of reaction zone (2) would be gradually increased by the reduction reaction of silica and carbon with reaction time [11-13]. The $\mathrm{SiO}$ vapor in case of reaction zone (1) was supplied from the silica-carbon reaction of reaction zone (2) and its partial pressure was estimated to be in the range of $0.8 \sim 0.9$ bar. The $\mathrm{SiO}$ vapor partial pressure is calculated from the some data regarding carbothermal reduction process $[6,16,17]$, while reaction zone (2) wrapped with 


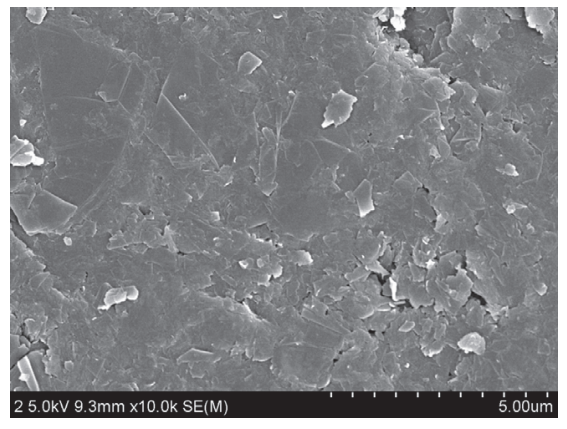

(a)

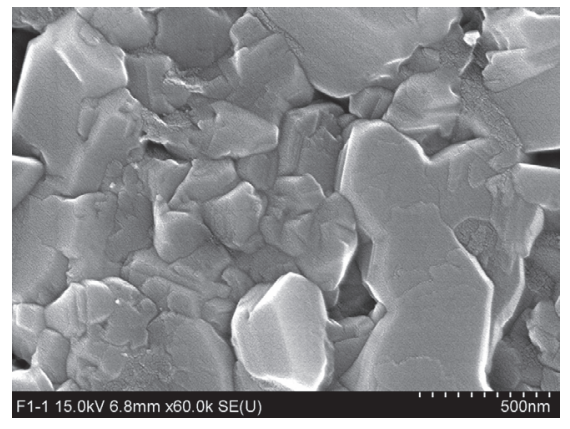

(b)

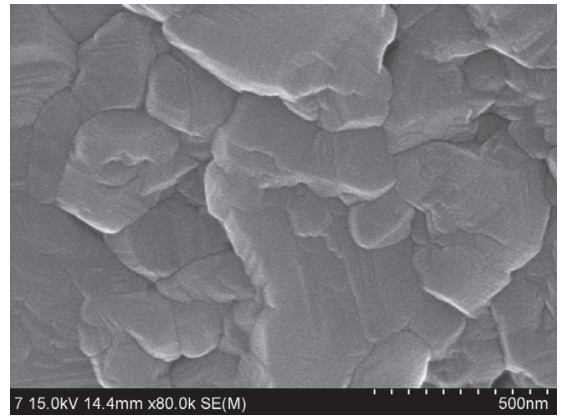

(c)

FIGURE 2: Surface morphologies of (a) bare graphite, the SiC-coated graphite pebbles prepared (b) at reaction zone (1) and (c) at reaction zone (2).

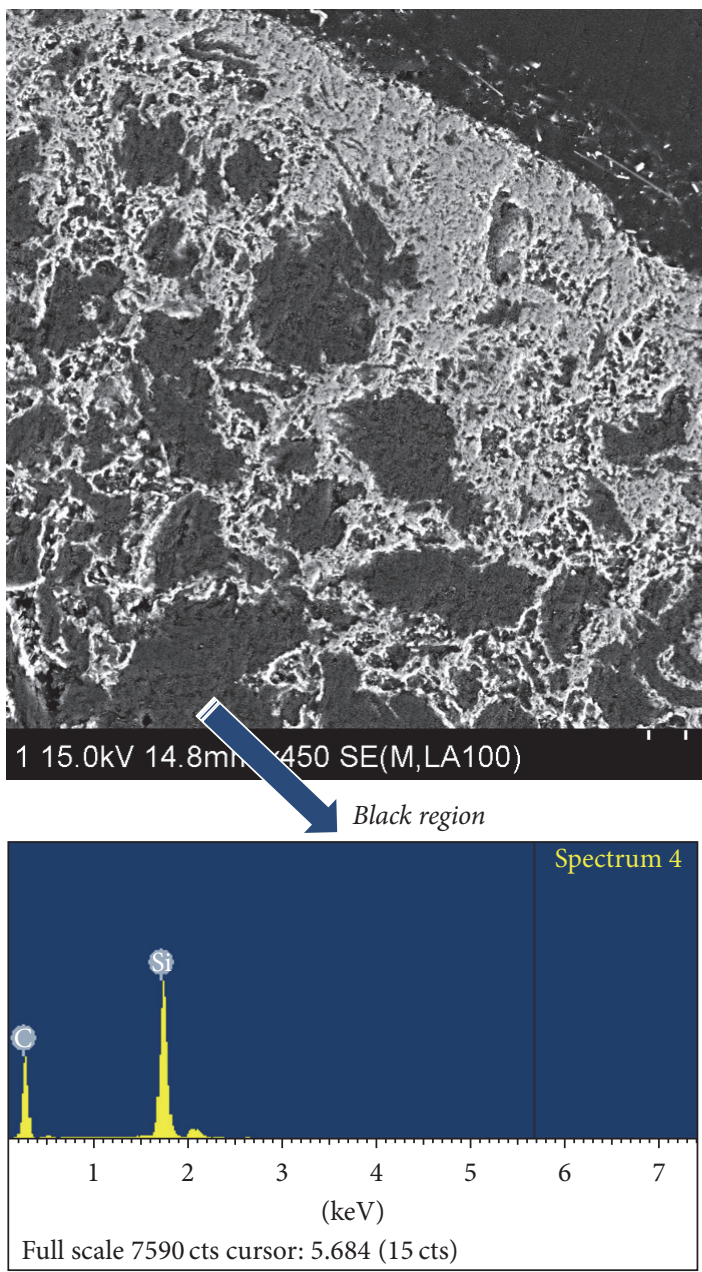

Element Weight\% Atomic\%

$\begin{array}{lll}\text { C K } & 76.81 & 88.57\end{array}$

$\begin{array}{lll}\text { Si K } & 23.19 & 11.43\end{array}$

Totals

FIGURE 3: Backscattered images and EDS analysis of cross-sectional SiC conversion coating on graphite (reaction zone (2)). 


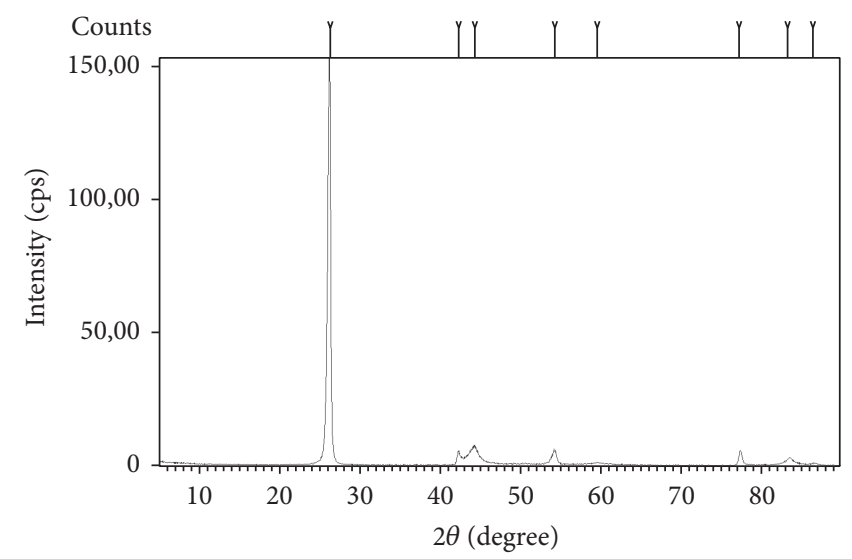

(a)

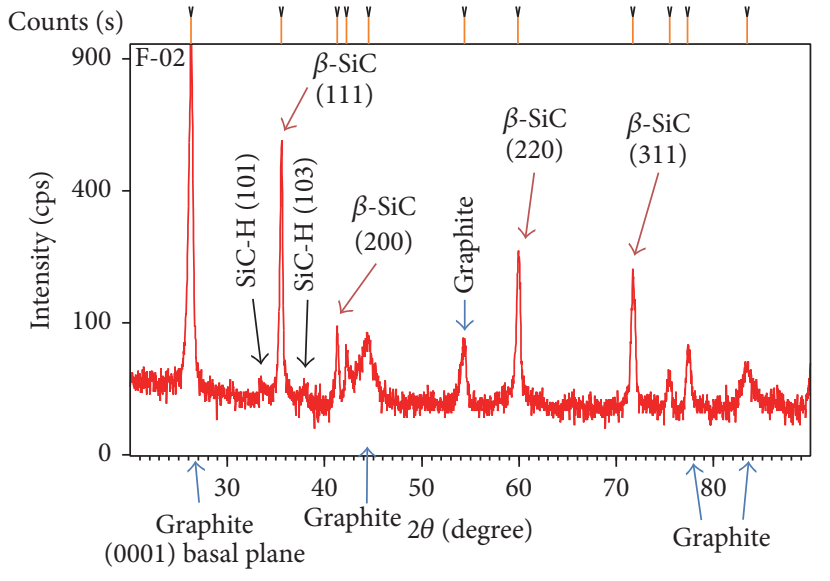

(b)

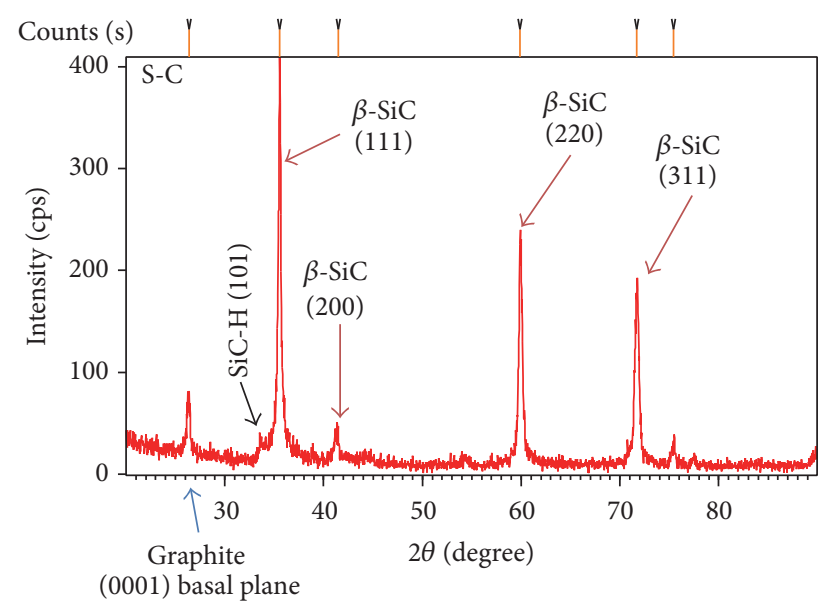

(c)

FIGURE 4: X-ray diffraction patterns of (a) grinded bare graphite, SiC-coated graphite prepared (b) at reaction zone (1) and (c) at reaction zone (2). $\beta$-SiC: cubic phase; $\mathrm{SiC}-\mathrm{H}$ : hexagonal phase.

silica melt in graphite crucible would have rather high vapor pressure as compared to that of reaction zone (1). Therefore, it seemed that the specimen in reaction zone (2) is exposed to higher $\mathrm{SiO}$ vapor pressure than that of reaction zone (1). The $\mathrm{SiO}$ vapor pressure in the silica melt bubble (reaction zone (2)) would be increased to the range of approximately $1 \sim 3$ bar with increasing reaction time. After reaction process, the size of the silica bubble was enlarged by $2 \sim 3$ times of graphite specimen. Thus, in reaction zone (2), the reaction of $\mathrm{SiO}$ vapor and graphite would induce rapid formation of $\mathrm{SiC}$ coating on bare graphite. The $\mathrm{SiO}$ vapor is infiltrated into graphite specimen and then the reaction of $\mathrm{SiO}$ vapor and graphite grains creates $\mathrm{SiC}$ grains.

The XRD patterns of $\mathrm{SiC}$ conversion coating layers formed on graphite are shown in Figure 4. The XRD pattern of surface region of the specimens showed mainly cubic 3C-SiC, referred to as $\beta$-SiC, crystalline phase of strong peaks corresponding to the (111), (220), and (311) planes. Particularly, the specimen (Figure 4(c)), fabricated at reaction zone (2), showed very high $\mathrm{SiC}$ peak intensity with small graphite peak. Although (111) peak intensity of the $\mathrm{SiC}$ coating on graphite prepared at reaction zone (1) was detected, very high (0001) peak of the graphite is shown (Figure 4(b)). The intensity difference of graphite peaks of Figures 4(b) and 4(c) represents different conversion reaction rate according to the $\mathrm{SiO}$ partial pressure in their reaction zones. The graphite in reaction zone (2), confined with silica melt at high temperature, has relatively high $\mathrm{SiO}$ vapor pressure; thus its conversion rate for coating formation would be rather fast when compared to the that of reaction zone (1). In addition, the coating specimen showed weak hexagonal SiC peaks of (101) (Figures $4(\mathrm{~b})$ and 4(c)) as well as (103) plane (Figure 4(c)). The cubic $\beta$ $\mathrm{SiC}$ structure has been considered to be the low-temperature polymorph of SiC. In this study, the presence of the hexagonal $\mathrm{SiC}$ might be explained as a result of polymorphic transformation of cubic $\mathrm{SiC}$, created from the reaction between $\mathrm{SiO}$ vapor and graphite at high temperature. It seemed that the structure transformation from $\beta$-SiC (cubic structure) to $\alpha$ $\mathrm{SiC}$ (hexagonal structure) is followed by simply a subsequent cool-down at high temperature over $1500^{\circ} \mathrm{C}$ under $\mathrm{Ar}$ atmosphere $[14,15]$. The SiC conversion coating layers formed on graphite were analyzed by FE-TEM (Figure 5). The fine 


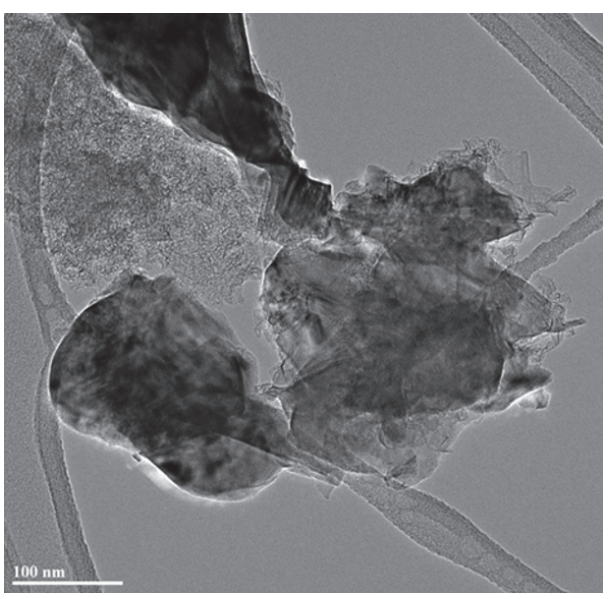

Fragment sample separated from conversion coating layer

(a)

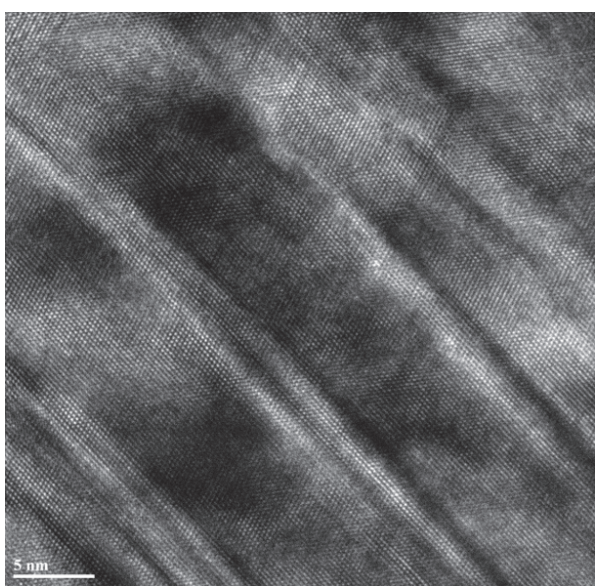

HRTEM image

(c)

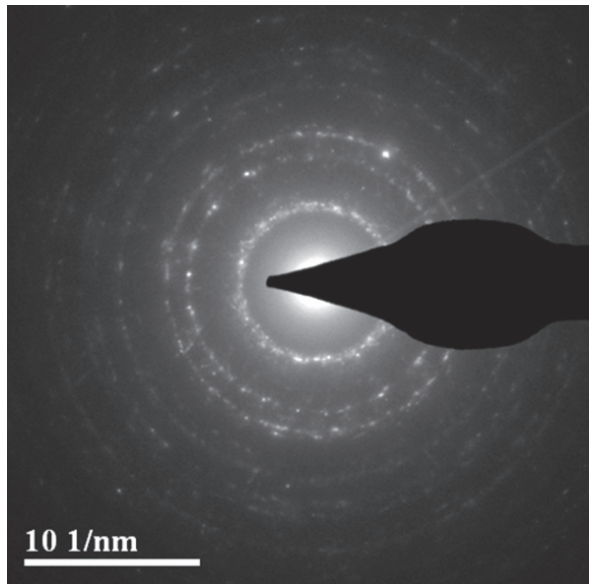

SAD pattern (\#75-1541H, \#75-0254C)

(b)

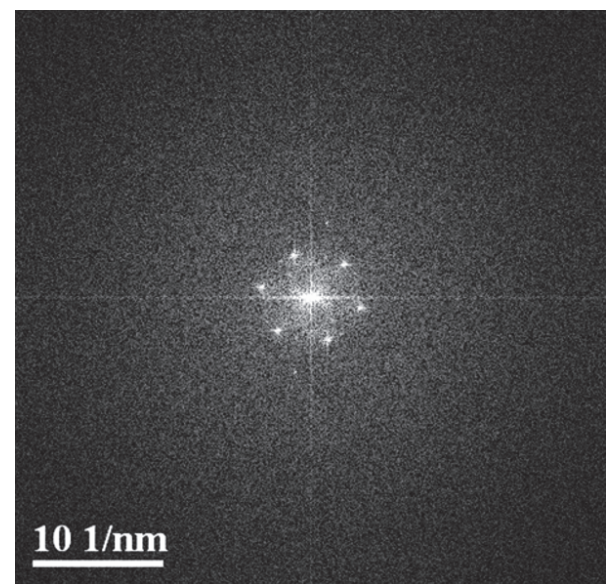

FFT pattern C [110]

(d)

Figure 5: FE-TEM images and diffraction patterns of SiC conversion coating.

particles in the conversion coating layers showed crystalline phases of SiC. The stacking faults are visible in the HRTEM image (Figure 5(c)) of the fragment sample, separated from the conversion coating layer. The SAD pattern of the fragment samples separated from coating layers showed both cubic and hexagonal SiC structure (Figure 5(b)).

Pore size distribution of the SiC-coated graphite and bare graphite was tested (Figure 6). After formation of $\mathrm{SiC}$ coating on graphite, the specimen, obtained at reaction zone (1), showed major peak of $1 \sim 2 \mu \mathrm{m}$ in diameter. The coated graphite showed the decrease of porosity compared to bare graphite. The difference in pore size distribution pattern of the coated graphite would be due to higher $\mathrm{SiO}$ vapor pressure.

Oxidation behavior of the SiC-coated graphite was measured by DSC/TGA instrument (Figure 7). The bare graphite (Figure 7(a)) was severely oxidized showing strong exothermic curve in the exposure condition $\left(\right.$ at $\left.700^{\circ} \mathrm{C}\right)$ to air blowing in less than $2 \mathrm{hrs}$. While the coated graphite, obtained at reaction zone (1), showed a significant weight loss to $24.3 \mathrm{wt} \%$, the specimen, coated at reaction zone (2), showed relatively low weight loss. The $\mathrm{SiC}$-coated graphite (Figures 7(b) and 7(c)) showed small weight loss to air at elevated temperature in the oxidation test. The decrease in the porosity of the coated graphite would imply the densification by the formation of the conversion layer in surface region. Finally, the $\mathrm{SiC}$ conversion coatings could be easily formed on graphite substrate using graphite furnace through chemical vapor reaction process.

\section{Conclusions}

The crystalline $\mathrm{SiC}$ conversion coatings were formed over the graphite. The surface coating layers showed the XRD peaks of (111), (220), and (311) planes of cubic SiC phase and 


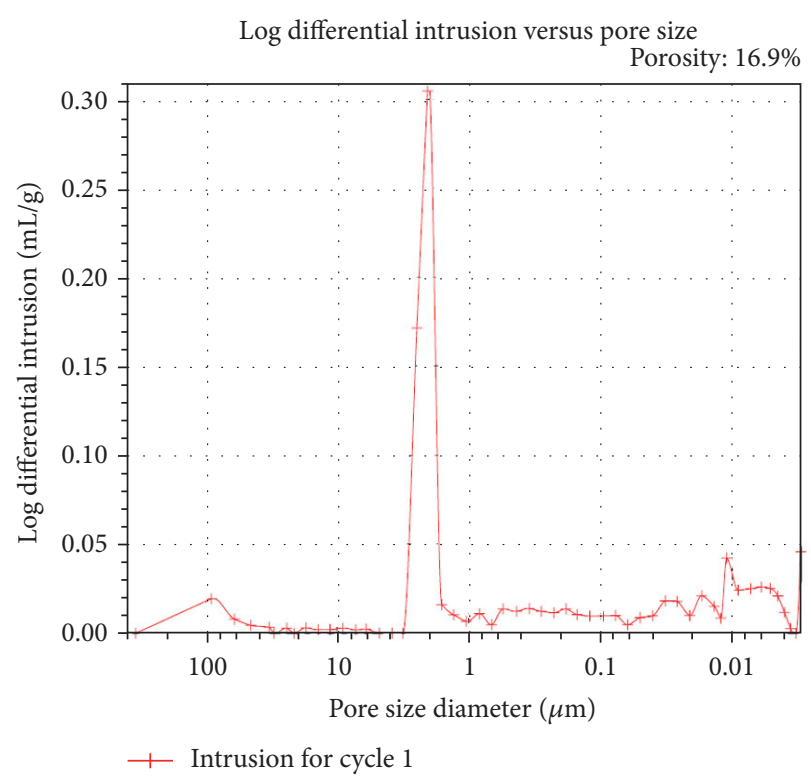

(a)

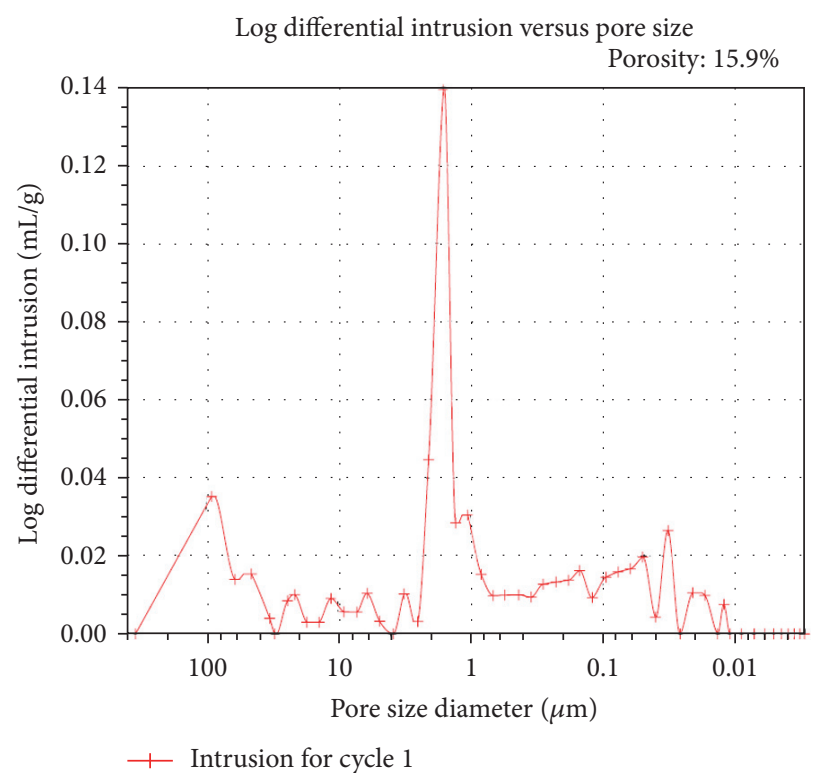

(b)

Log differential intrusion versus pore size

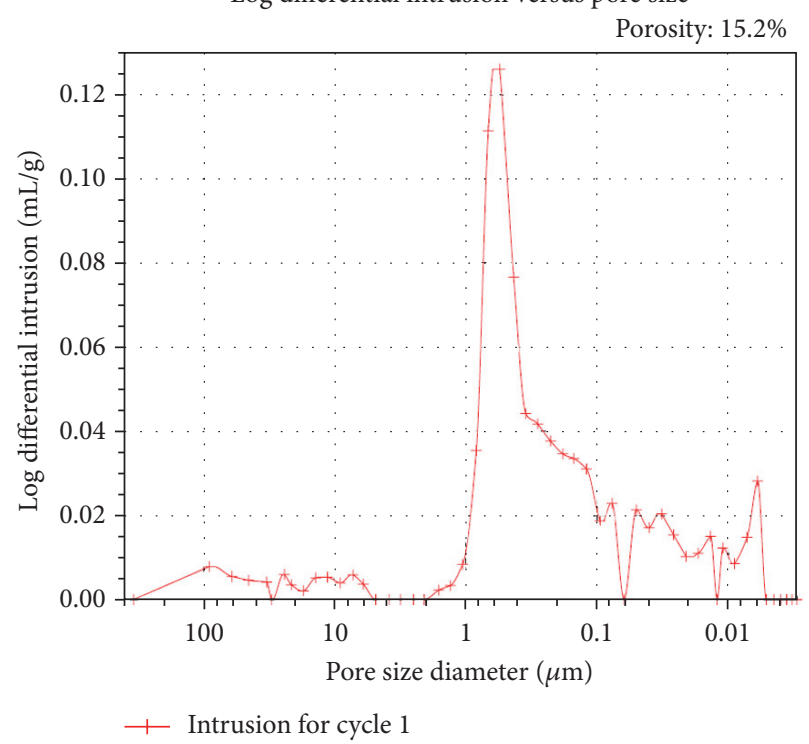

(c)

FIgURE 6: Pore size distribution and porosity for (a) graphite, SiC-coated graphite prepared (b) at reaction zone (1) and (c) at reaction zone (2).

very weak hexagonal $\mathrm{SiC}$ peaks. The crystalline pattern and stacking faults of the conversion coating grains were observed in HRTEM image. The cubic SiC structure of the conversion coating was identified in FFT pattern of cubic (110). A dense surface morphology of the $\mathrm{SiC}$-coated graphite was observed by FE-SEM. According to the conversion reaction conditions, the $\mathrm{SiC}$ coatings showed somewhat different XRD pattern and oxidation behavior. It was inferred that these results are based on rather faster $\mathrm{SiC}$ conversion rate from graphite in reaction zone (2).

\section{Competing Interests}

The authors declare that they have no competing interests.

\section{Acknowledgments}

This work was supported by R\&D Program through National Fusion Research Institute (NFRI) funded by the Ministry of Education, Science and Technology of the Republic of Korea (NFRI-IN1203). This research was supported by Basic 


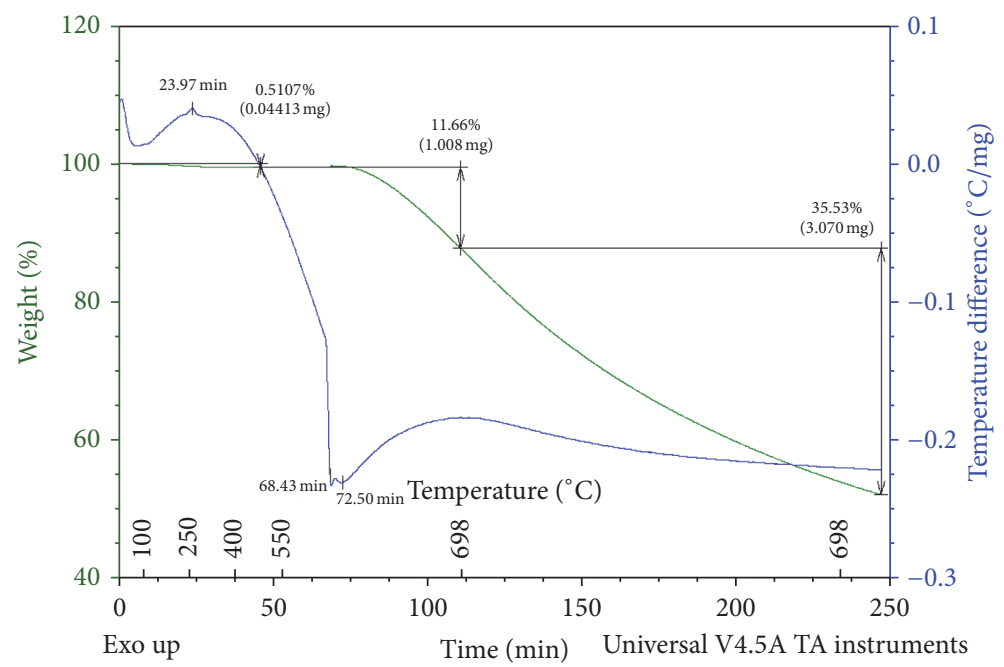

(a)

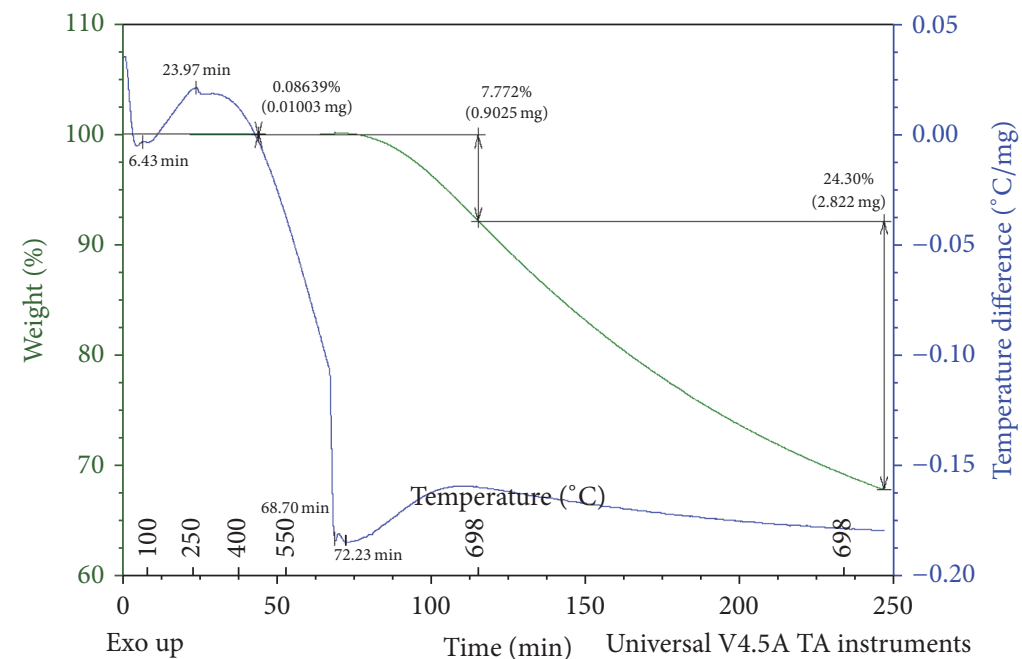

(b)

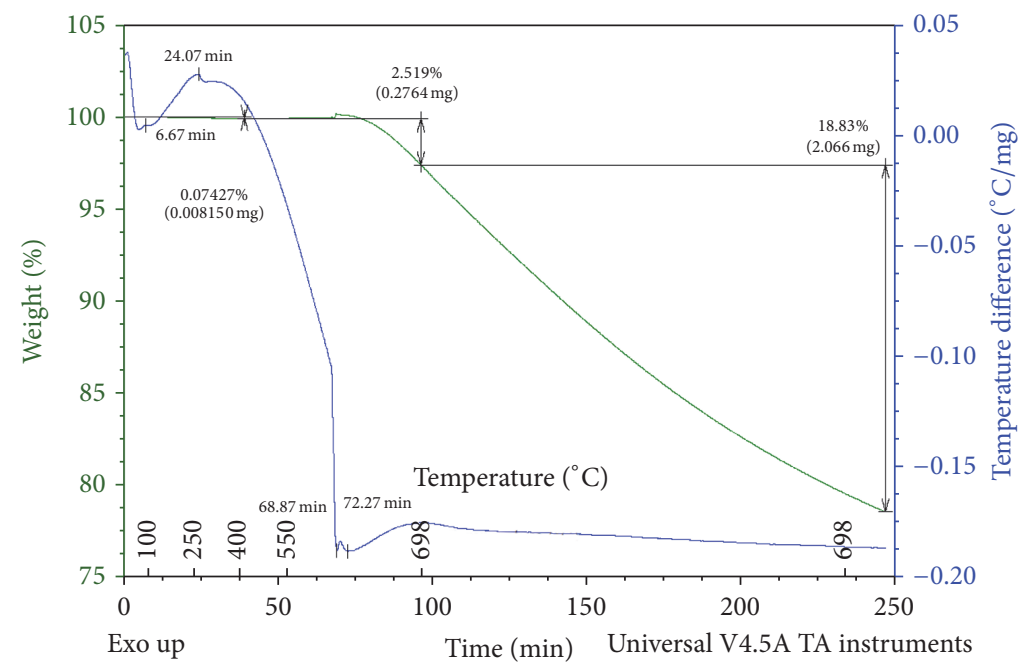

(c)

Figure 7: DSC/TGA results for (a) graphite, SiC-coated graphite prepared (b) at reaction zone (1) and (c) at reaction zone (2) with air blowing $(100 \mathrm{~mL} / \mathrm{min}) .10^{\circ} \mathrm{C} / \mathrm{min}$ to $700^{\circ} \mathrm{C}$ in Ar gas and holding $180 \mathrm{~min}$ in air. 
Science Research Program through the National Research Foundation of Korea (NRF) funded by the Ministry of Education (NRF-2013R1A1A2065604). This study was supported by research fund from Chosun University, 2015.

\section{References}

[1] O. Yamamoto, K. Imai, T. Sasamoto, and M. Inagaki, "Preparation of carbon material with $\mathrm{SiC}$-concentration gradient by silicon impregnation and its oxidation behaviour," Journal of the European Ceramic Society, vol. 12, no. 6, pp. 435-440, 1993.

[2] T. L. Dhami, O. P. Bahl, and B. R. Awasthy, "Oxidation-resistant carbon-carbon composites up to 1700 ॰C, Carbon, vol. 33 , no. 4 , pp. 479-490, 1995.

[3] Q. Zhu, X. Qiu, and C. Ma, "Oxidation resistant SiC coating for graphite materials," Carbon, vol. 37, no. 9, pp. 1475-1484, 1999.

[4] J. D. Buckley and D. D. Edie, "High-temperature coatings on carbon fibers and carbon-carbon composites," in CarbonCarbon Materials and Composites, Noyes Publications, Upper Saddle River, NJ, USA, 1993.

[5] S. H. Moon, H. K. Yoon, R. Murakami, T. G. Kim, S. Cho, and I. K. Yu, "The effects on heat treatment of SiC coated / graphite plate by RF sputtering system," International Journal of Modern Physics: Conference Series, vol. 6, pp. 757-761, 2012.

[6] J. J. Biernacki and G. P. Wotzak, "Stoichiometry of the $\mathrm{C}+\mathrm{SiO}_{2}$ Reaction," Journal of the American Ceramic Society, vol. 72, no. 1, pp. 122-129, 1989.

[7] Y. T. Kim, C. S. Jang, J. W. Choi, and E.-S. Kim, "Comparison of thermal shock behavior of $\mathrm{SiC}$ coating deposited on graphite substrates by chemical vapor reaction and physical vapor transport," Journal of Ceramic Processing Research, vol. 15, no. 5, pp. 277-280, 2014.

[8] N. S. Jacobson, K. N. Lee, and D. S. Fox, "Reactions of silicon carbide and silicon(IV) oxide at elevated temperatures," Journal of the American Ceramic Society, vol. 75, no. 6, pp. 1603-1611, 1992.

[9] R. E. Booth, D. M. Shuford, and J. S. Linck, "Conversion coating on carbon/carbon composites with controlled microstructure," U.S. Patent no. 5,330,789, 1994.

[10] Y.-H. Yun and S.-C. Choi, "Microstructural characterization and residual stress distribution of chemical vapor reaction $\mathrm{SiC}$ conversion layers on the 'continuous' and 'discontinuous' graphite," Journal of the Ceramic Society of Japan, vol. 108, no. 12, pp. 1045-1051, 2000.

[11] D. C. Sayles, "Method of manufacturing hybrid fiber-reinforced composite nozzle material,” U. S. Patent No. 5,525,372, 1996.

[12] Y.-H. Yun, Y.-H. Park, M.-Y. Ahn, and S. Cho, "CVR-SiC coating of graphite pebbles for fusion blanket application," Ceramics International, vol. 40, no. 1, pp. 879-885, 2014.

[13] Y. Lee, Y.-H. Yun, Y.-H. Park, M.-Y. Ahn, and S. Cho, "Surface coating of graphite pebbles for Korean HCCR TBM," Fusion Engineering and Design, vol. 89, no. 7-8, pp. 1734-1738, 2014.

[14] I. S. Gorban and G. N. Mishinova, "The bases of luminescent diagnostic of dislocation structure of SiC crystals," in SPIE Proceedings of the International Conference on Optical Diagnosis of Materials and Devices for Opto-, Micro and Quantum Electronics, pp. 187-196, SPIE, Kiev, Ukraine, May 1997.

[15] S. I. Vlaskina, G. N. Mishinova, V. I. Vlaskin, V. E. Rodionov, and G. S. Svechnikov, "3C-6H transformation in heated cubic silicon carbide 3C-SiC," Semiconductor Physics, Quantum Electronics and Optoelectronics, vol. 14, no. 4, pp. 432-436, 2011.
[16] A. W. Weimer, "Thermochemistry and kinetics," in Carbide, Nitride and Boride Materials Synthesis and Processing, pp. 9497, Chapman \& Hall, London, UK, 1st edition, 1997.

[17] I. Yajima, M. Doi, and T. Kuramoto, Sinterability of Submicron $\beta$-SiC Powder Synthesized by Carbothermal Reduction of Silica, New Materials Series, SiC Ceramics, Uchida Rokakuho, Tokyo, Japan, 1988. 

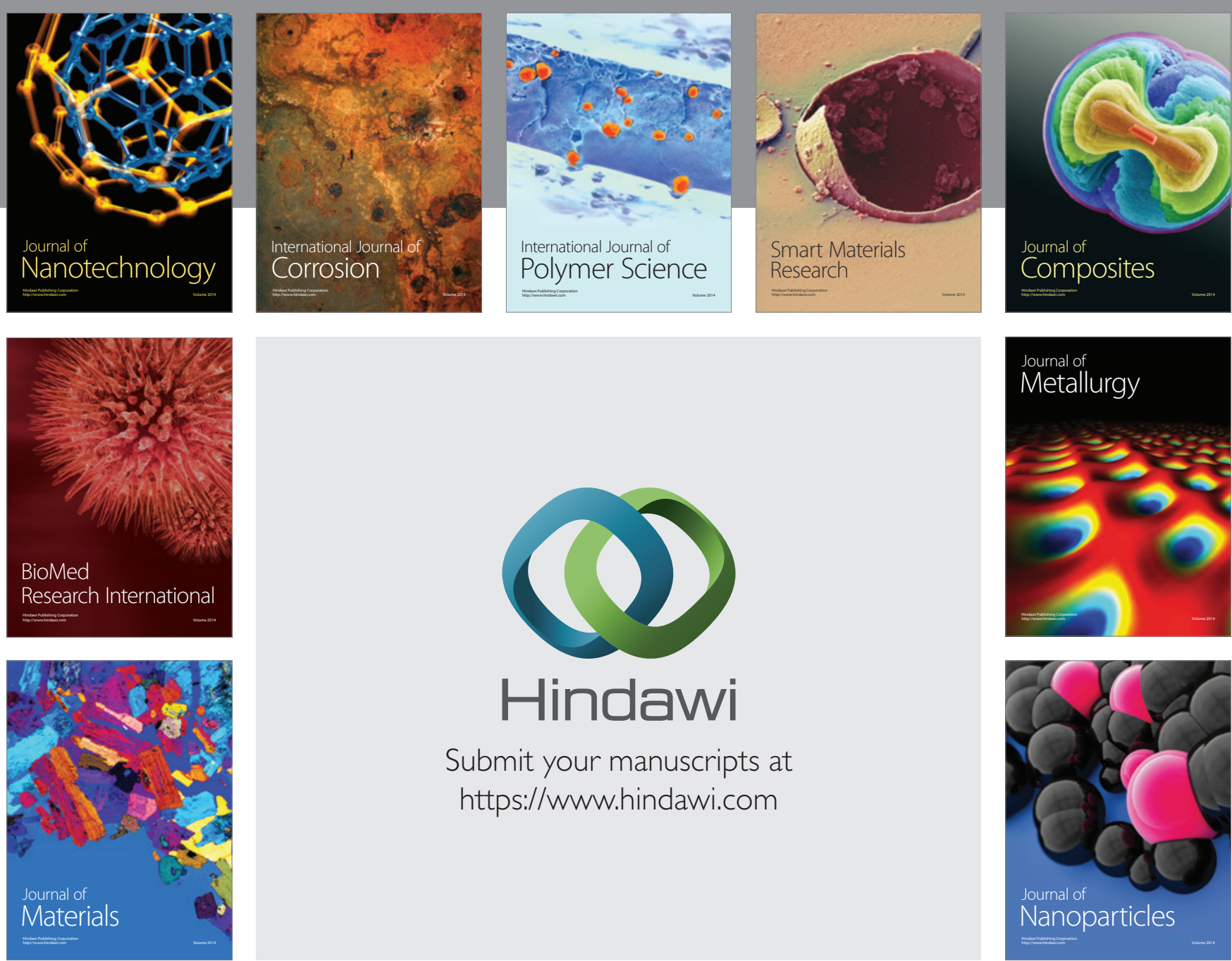

\section{Hindawi}

Submit your manuscripts at

https://www.hindawi.com

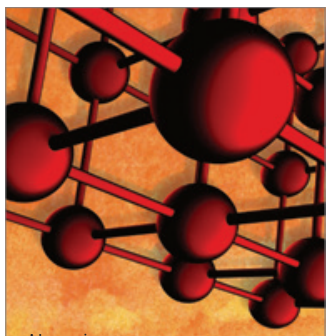

Materials Science and Engineering
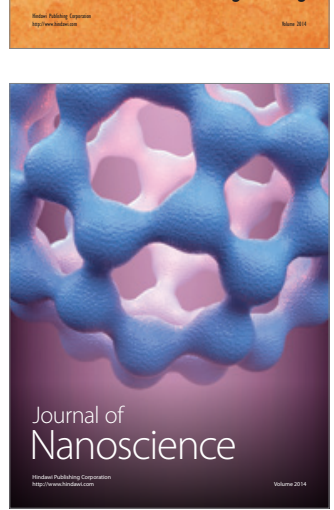
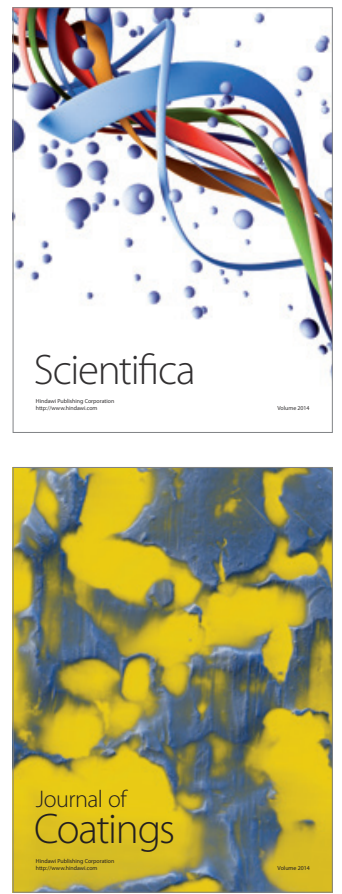
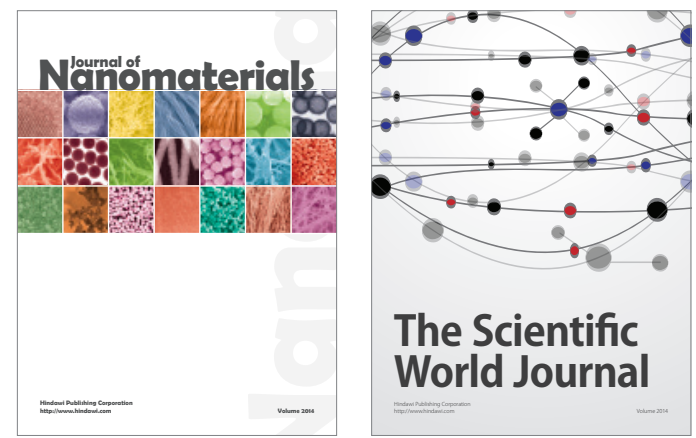

The Scientific World Journal
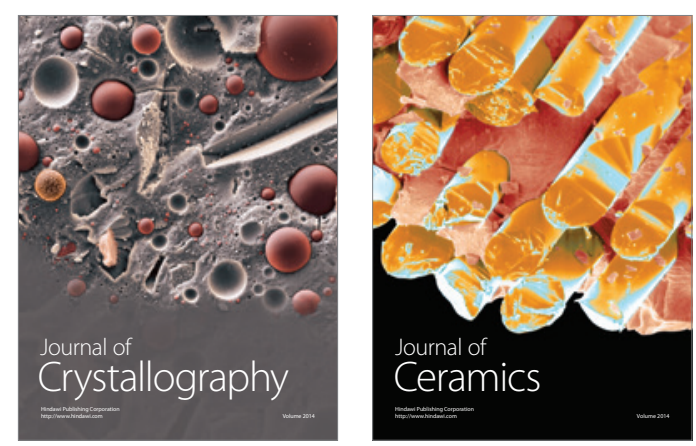
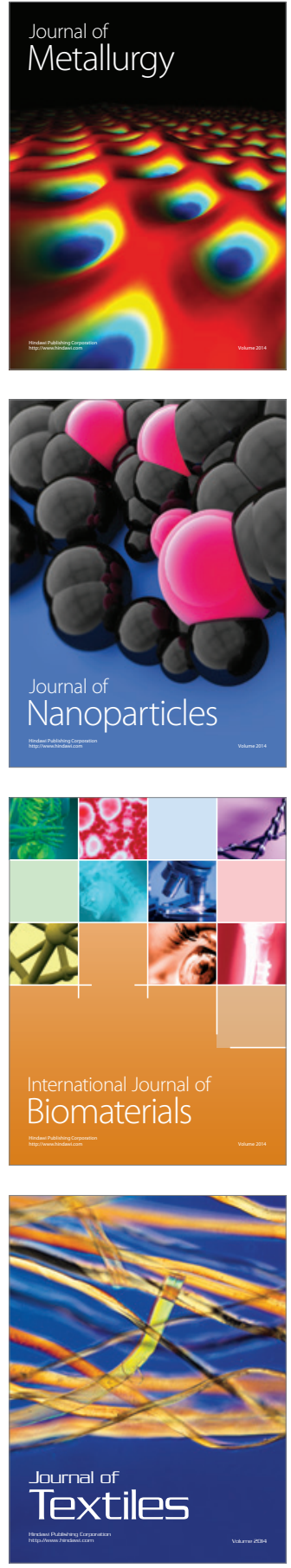